\title{
Normative data for the Hospital Anxiety and Depression Scale
}

Suzanne Breeman ${ }^{1}$, Seonaidh Cotton ${ }^{1}$, Shona Fielding ${ }^{2}$, Gareth T Jones ${ }^{3}$

1 Health Services Research Unit, Division of Applied Health Sciences, University of Aberdeen, Health Sciences Building, Foresterhill, Aberdeen, AB25 2ZD, UK

2 Medical Statistics Team, Division of Applied Health Sciences, University of Aberdeen, Polwarth Building, Foresterhill, AB25 2ZD, UK

3 Epidemiology Group, Institute of Applied Health Sciences, University of Aberdeen, Polwarth Building, Foresterhill, AB25 2ZD, UK

Corresponding author:

Suzanne Breeman

Email: s.breeman@abdn.ac.uk

Tel: 01224438169

Fax: 01224 438165; 


\section{Purpose}

The Hospital Anxiety and Depression Scale (HADS) is widely used in both research and clinical contexts. However UK normative data from HADS remains limited. In our recent review of the literature, only six reports from four studies were identified as reporting UK normative data and all had limitations. The aim of our study was to use a large population-based dataset to address this.

\section{Methods}

The Epidemiology of Functional Disorders Study is a large longitudinal populationbased study carried out in Northwest England. All adults aged between 25 and 65 years registered with three general practices were sent a self-completion questionnaire which contained the HADS and other health-related instruments.

Scores were calculated for participants completing all items on each sub-scale (anxiety 6189 participants, depression 6198 participants). Scores are presented by gender and by 5-year age-groups. Percentile scores were also generated.

\section{Results}

The median anxiety score was higher in women (6, IQR 4 to 9) than in men (5, IQR 2 to 8), and increased with age in both groups. The median depression score for both women and men was 3 (IQR 1 to 6).

\section{Conclusions}

Our study is the largest population-based study providing UK normative data from HADS. While our data confirms some of the normative data reported previously, subtle and important differences emerged, particularly at the upper end of the percentile scores. Due to the nature of our study design and the number of 
participants sampled, we believe that our data is likely to be more representative of the UK population than existing published normative values. 


\section{Introduction}

Patient reported outcome measures (PROMs) are extensively used in research and medical practice to assess clinical outcomes such as health-related quality of life [1, 2]. They are a subjective measure and assess the outcome or health parameter from the patient's own perspective $[1,2]$. In the field of mental health, PROMs have been shown to provide unique and invaluable information [3]. One such instrument is the Hospital Anxiety and Depression Scale (HADS) [4]

The HADS was originally developed by Zigmond and Snaith as a screening tool to capture clinically significant states of anxiety and depression in a non-psychiatric hospital setting [4]. The HADS was therefore designed to be a brief, 14-item, selfassessment scale that was easily understandable and capable of distinguishing between these emotional states [5].

The anxiety and depression sub-scales each consist of seven items with each item having four possible answers scored 0, 1, 2 or 3. Individual anxiety and depression scores are calculated by summation of the appropriate seven items and thus can range from zero to twenty-one, with higher scores indicating higher levels of anxiety or depression respectively.

In their initial publication, Zigmond and Snaith used clinical assessments to recommend that a score of 0 to 7 on either sub-scale should be defined as a 'noncase' (later defined as 'normal'), a score of between 8 and 10 defined as a 'doubtful case' (later defined as a 'mild case') and a score of more than or equal to 11 defined as a 'definitive case' of anxiety or depression [4]. However they emphasised that further research would be required to validate the suggested cut-off scores in different clinical settings. Furthermore, in a more recent publication, the authors suggest a third cut-off point, where a score of between 11 and 14 is defined as a 
'moderate' case and a score of between 15 and 21 as a 'severe' case of anxiety or depression [5]. However, no empirical data was presented on the usefulness of this later cut-off score $[5,6]$.

Since its development the HADS has become a commonly used instrument in both research and clinical practice. For example, a review published by Herrman in 1997 identified over 200 published papers which reported on the use of HADS in approximately 35,000 participants [6]. The studies were conducted in 26 different countries; the questionnaire translated into 33 different languages; and was used in many different medical settings, for example general medicine, oncology and cardiology. An updated review by Bjelland et al in 2002 reported that the number of papers reporting HADS had since increased almost fourfold, highlighting the continued use of the questionnaire in both standard medical practice and in healthrelated research [7].

Despite its frequent use, normative data (i.e. data collected from a representative sample of the general population against which all subsequently collected data can be compared) has remained limited. Our recent review of the literature identified only twenty papers that could be described as reporting normative data from HADS [8-27]. The studies were conducted mainly in Europe, included sample sizes ranging from 94 [17] to 62,344 [13] participants and were sourced using a variety of different techniques, for example all residents in a particular region/country $[13,17,19]$, a stratified random sample of three age cohorts $[12,20]$ and adults registered with a particular Primary Care practice $[8,10,14]$.

Only six reports from four studies included UK participants [8, 12, 14, 15, 20, 24]. All reports had limitations, mainly in terms of sample size and/or sample selection. One of these studies [15] is recommended by the current licence holder (GL Assessment) 
as appropriate normative data for the UK. However the sampling technique employed in this study (participants were drawn from commercial and public service organisations, community centres and recreational clubs) means that the data is unlikely to be representative of the general population, as it may only include those in employment or engaged in community activities, who may have different psychological morbidity from those that are not.

The aim of the current study was to establish normative HADS data for the UK population using data from a large population based study which is likely to be representative of the UK population.

\section{Methods}

The Epidemiology of Functional Disorders (EpiFunD) Study is a large longitudinal population-based study carried out in Northwest England, the design and primary results of which have been published previously $[28,29]$. In brief, at baseline, all patients registered with one of three general practices (although not necessarily attending for treatment) were sent a self-completion questionnaire in 2001/02. The practices were from different socio-economic areas, as assessed by the Townsend index - a census-derived index of indicators of home ownership, car ownership, unemployment and overcrowding [30]. The questionnaire included the HADS and other health related instruments. Two weeks after the initial mailing, non-participants were sent a reminder postcard, with another full questionnaire sent two weeks subsequently to those who had still not responded. The study was approved by South Manchester local research ethics committee and South Cheshire local research ethics committee.

In this analysis, we report baseline data. All analyses were performed using the statistical package Stata Version 10.0 (StataCorp, College Station, TX). To estimate 
the representativeness of the EpiFunD sample, the age and gender profiles of the sample was compared to UK national estimates (2001 Census data [31]). The internal validity of the sample were then assessed by comparing response rates by gender and age using the Chi-Square test.

\section{Anxiety and Depression scores}

Anxiety and depression scores were calculated for those who had completed all items on the anxiety and depression sub-scales respectively (complete case analysis). A priori, we hypothesised that scores would differ by gender and age [827]; this was confirmed in the initial analysis and thus results are presented for females and males separately, and within gender, by 5-year age-group.

As the anxiety and depression scores were skewed towards lower scores (positively skewed distribution), median scores with the associated Interquartile Range (IQR) were deemed the most appropriate descriptive statistic to present. However to aid comparisons with other studies, data is presented here in four ways: (1) median scores with IQRs; (2) the proportion of patients in each of Zigmond and Snaith's [4] original normal, mild and moderate to severe classifications; (3) percentile scores and; (4) mean scores with the associated Standard Deviations (SD).

\section{Results}

\section{Profile of EpiFunD sample versus Census data}

The EpiFunD baseline questionnaire was issued to 10,987 adults and had a response rate of $68.2 \%$ (after adjusting for deaths and those not resident at the given address) [30]. Of those issued with the questionnaire, $50.2 \%$ were female and $49.8 \%$ were male. These proportions were similar to the 2001 Census data which showed that $50.7 \%$ of UK adults aged between 25 and 65 years of age were female 
[31]. The age distribution of those sent the questionnaire was also similar to that reported in the 2001 Census data [31].

\section{Profile of responders}

Response rates were higher in women $(64.3 \%)$ than men $(49.8 \%)(p<0.001)$ and generally increased with increasing age $(41.3 \%$ in the youngest group to $72.1 \%$ in the oldest group; $p<0.001$ ). The participants that returned the questionnaire were also younger when compared to non-responders (mean age 45.9 (SD 11.0) versus 42.0 (SD 10.6)). The baseline characteristics of the responders are shown in Table 1.

\section{Level of missing data}

Of the 6,280 participants who completed the questionnaire, $1.4 \%$ (91) of the participants failed to complete all seven items which contribute to the anxiety score and $1.3 \%$ (82) failed to complete all seven items which contribute to the depression score. Imputation of missing data for those participants that had missed one or two items on the anxiety scale (50 and three participants respectively) or had missed one or two items on the depression scale (40 and 13 participants respectively) had minimal impact on the reported scores and prevalence rates. The results presented below are therefore based on a complete case analysis only.

\section{Anxiety}

The median anxiety scores were significantly higher among women (6, IQR 4 to 9) than among men (5, IQR 2 to 8 ; $p<0.001 ;$ Table 2). Similarly, the percentage of those classified as having 'moderate to severe' anxiety (anxiety score $\geq 11$ ) was higher among women (19.0\%) than among men $(12.5 \%$; $\mathrm{p}<0.001)$. In both women and men, the median anxiety scores and the prevalence of 'moderate to severe' anxiety decreased with increasing age, although this was not statistically significant. The anxiety scores are presented as percentiles for women and men separately 
(Figure 1). For comparison, these are plotted together with the percentile data from Crawford et al [15], the study providing the currently recommended normative data from the UK.

\section{Depression}

The median depression scores were the same for both women and men (3, IQR 1 to 6; Table 3). The percentage of those classified as having 'moderate to severe' depression (depression score $\geq 11$ ) was also the same among women $(6.9 \%)$ and men (6.9\%), although the percentage of those classified as having any level of depression (depression score >8) was higher among women (17.2\%) than in men (15.4\%). In both men and women, the percentage of those classed as having 'moderate to severe' depression had an apparent bell-shape with respect to age, with the highest prevalence seen in participants in their forties and early fifties. Percentile data is shown in Figure 2, and plotted together with the percentile data from Crawford et al [15].

\section{Discussion}

The EpiFunD study was used as a means to expand the available UK normative data for HADS. This study is a large population-based study that invited all adults, aged between 25 and 65 years of age, who were registered with three primary care practices in the North-West of England, to participate [32]. This invited group were shown to be broadly representative of the UK population in terms of age and gender when compared to the 2001 Census statistics.

Compared to men, response rates were higher in women, as were anxiety scores. Thus, combining the anxiety scores for men and women would result in artificially inflated summary measures for men and artificially reduced summary measures in woman. For this reason (and our a priori hypothesis that scores would differ by 
gender), we have not combined the data and have presented summary scores for men and women separately. Response rates also varied by age, as did anxiety and depression scores, and combined these factors have the potential to distort the findings of the study if presenting single normative values across different ages and genders.

\section{Strengths and limitations of the study}

A particular strength of this study is the sample size, which is more than three times greater than the study recommended as providing normative data for the UK [15] and which allows us to report summary scores by gender and 5-year age-groups.

Furthermore, we suggest that those completing the HADS as part of the EpiFunD study are likely to be more representative of the general population than participants of the study providing the currently recommended normative data from the UK [15], particularly because of the different sampling techniques. Crawford et al drew their sample from commercial and public service organisations, community centres and recreational clubs [15]. By comparison the EpiFunD sample was drawn from the registers of three primary care practices. It is estimated that $96 \%$ of the UK population are registered with a GP [33] and, thus, sampling from GP registers provides a convenient population sampling frame for health research and, arguably, a more appropriate population from which to derive normative values of any health instrument.

However, as the proportion of people over 60 years of age is reported to be growing faster than any other age group in the UK [34], one limitation of this study is the age range of the participants included: the EpiFunD sample only contained adults aged 25 to 65 years of age. Therefore, while this paper represents a population-based sample of adults of working age, extrapolation to older adults is limited. 


\section{Comparisons with current literature}

We have confirmed some of the findings reported by Crawford et al [15]. For example, we report the same median anxiety and depression scores for both men and women. However, although there are similarities between our data and the data from Crawford et al [15], there are subtle but important differences. For example, the distributions of percentiles diverged at the upper end of the scores, with a greater proportion of the EpiFunD sample having higher scores on each of the sub-scales compared with the Crawford et al study [15]. There are a number of possible explanations for this. Firstly, anxiety and depression scores vary by age, and the Crawford et al study [15] included a higher proportion of younger participants (28\% of participants were aged 18-29 years) compared to the current study (where $8 \%$ of participants were aged $<30$ years). However as noted previously, a strength of our study is the sample size, which allows summary scores to be calculated by gender and age group. Secondly, it is likely that those participating in the study by Crawford et al, by their very nature (i.e. they are participating in activities or work outside the home) have less psychological morbidity (and thus report lower anxiety and depression scores) than those who do not participate in such activities (and who may be included in our study) [35].

\section{Conclusions}

We have provided supplementary normative data for the HADS for the UK working age population (25-65 years) using data collected as part of the EpiFunD study. We believe that the data we report may be more representative of the general population than previous studies. In addition, the sample size allows data to be presented not only by gender but also by age-group. Such data will aid in the interpretation of other studies that have used the HADS as a patient reported outcome measure. 


\section{Acknowledgements}

The authors would like to thank all those involved in the EpiFunD study for their role in collecting the data used in this study, particularly the principal investigators Gary Macfarlane (University of Aberdeen) and John McBeth (Keele University, and the University of Manchester) who allowed use of the EpiFunD dataset. The EpiFunD study was funded by Arthritis Research UK (formerly the Arthritis Research Campaign), Grant number: 17552. 


\section{References}

1 Fitzpatrick, R., Davey, C., Buxton M., Jones, D.(1998). Evaluating patientbased outcome measures for use in clinical trials. Health Technology Assessment, 2(14), 1-86.

2 Department for Health. (2008). Guidance on the routine collection of Patient Reported Outcome Measures (PROMs). www.dh.gov.uk/publications.

3 Schmidt, L.J., Garratt, A.M., Fitzpatrick,,R. (2000). Instruments for Mental Health: a Review. Report from the Patient-reported Health Instruments Group (formerly the Patient-assessed Health Outcomes Programme) to the Department of Health.

4 Zigmond, A.S., Snaith, R.P. (1983). The Hospital Anxiety and Depression Scale. Acta Psychiatr Scand, 67, 361-370.

5 Snaith, R.P. (2003). The Hospital Anxiety and Depression Scale. Health Qual Life Outcomes, 1, 29-32.

6 Hermann, C. (1997). International Experiences with the Hospital Anxiety and Depression Scale - A review of validation data and clinical results. J Psychosom Res, 42(1), 17-41.

7 Bjelland, I., Dahl, A.A., Haug, T.T., Neckelmann, D. (2002). The validity of the Hospital Anxiety and Depression Scale: An updated literature review. J Psychosom Res, 52, 69-77.

8 Dowell, A.C., Biran, L.A. (1990). Problems in using the hospital anxiety and depression scale for screening patients in general practice. $\mathrm{Br} \mathrm{J}$ Gen Prac, 40, 27-28.

9 Lisspers, J., Nygren, A., Sodermann, E. (1997). Hospital Anxiety and Depression Scale (HAD): some psychometric data for a Swedish sample. Acta Psychiatr Scand, 96, 281-286.

10 Spinhoven, P.H., Ormel, J., Sloekers, P.A., Kempen, G.I.J.M., Speckens, A.E.M., Van Hemert, A.M. (1997). A validation study of the Hospital Anxiety 
and Depression Scale (HADS) in different groups of Dutch subjects. Psychol Med, 27, 363-370.

11 Groenvold, M., Fayers, P.M., Sprangers, M.A.G., Bjorner, J.B., Klee, M.C., Aaronson, N.K., Bech, P., Mouridsen, H.T. (1999). Anxiety and Depression in Breast Cancer Patients at Low Risk of Recurrence Compared with the General Population: A Valid Comparison? J Clin Epidemiol, 52(6), 523-530.

12 Dunbar, M., Ford, G., Hunt, K., Der, G. (2000). A Confirmatory factor analysis of the Hospital Anxiety and Depression Scale: Comparing empirical and theoretically derived structures. Br J Clin Psychol, 39, 79-94.

13 Stordal, E., Bjartveit Krüger, M., Dahl, N.H., Krüger, Ø., Mykletun, A., Dahl, A.A. (2001). Depression in relation to age and gender in the general population: the Nord-Trøndelag Health Study (HUNT). Acta Psychiatr Scand, $104,210-216$.

14 Kadam, U.T., Croft, P., Lewis, M. (2001). Use of a cross-sectional survey to estimate outcome of health care: The example of anxiety and depression. $\mathrm{J}$ Clin Epidemiol, 54, 1112-1119.

15 Crawford, J.R., Henry, J.D., Crombie, C., Taylor, E.P. (2001). Normative data for the HADS from a large non-clinical sample. $\mathrm{Br} \mathrm{J}$ Clin Psychol, 40, 429434

16 Beutel, M.E., Wiltink, J., Schwarz, R., Weidner, W., Brähler, E. (2002). Complaints of the ageing male based on a representative community sample. Euro Urology, 41, 85-93.

17 Bjelland, I., Tell, G.S., Vollset, S.M., Refsum, H., Ueland, P.M. (2003). Folate, Vitamin $B_{12}$, Homocysteine, and the MTHFR $677 \mathrm{C} \rightarrow T$ Polymorphism in Anxiety and Depression. Arch Gen Psychiatry; 60, 618-626.

18 Beutel, M.E., Weidner, K., Schwarz, R., Brähler, E. (2004). Age-related complaints in women and their determinants based on a representative community study. Eur J Obstet Gynecol Reprod Biol, 117, 204-212. 
19 Berg, A.M., Hem, E., Lau, B., Ekeberg, Ø. (2006). An exploration of job stress and health in the Norwegian police service: a cross-sectional study. J Occup Med Toxicol, 1, 26-34.

20 Mutrie, N., Hannah, M.K. (2007). The importance of both setting and intensity of physical activity in relation to non-clinical anxiety and depression. Int $\mathrm{J}$ Health Promot Educ, 45(1), 24-32.

23 Kilkkinen, A., Kao-Philpot, A., O'Neil, A., Philpot, B., Reddy, P., Bunker, S., Dunbar, J. (2007). Prevalence of psychological distress, anxiety and depression in rural communities in Australia. Aust $\mathrm{J}$ Rural Health, 15, 114119.

22 Welén, K., Faresjö, A., Faresjö, T. (2008). Functional dyspepsia affects women more than men in daily life: A case-control study in primary care. Gend Med, 5(1), 62-73.

23 Michopoulos, I., Douzenis, A., Kalkavoura, C., Christodoulou, C., Michalopoulou, P., Kalemi, G., Fineti, K., Patapis, P., Protopapas, K., Lykouras, L. (2008). Hospital Anxiety and Depression Scale (HADS): validation in a Greek general hospital sample. Ann Gen Psychiatry, 7, 4-8.

24 Crawford, J.R., Garthwaite, P.H., Lawrie, C.J., Henry, J.D., MacDonald, M.A., Sutherland, J., Sinha, P. (2009). A convenient method of obtaining percentile norms and accompanying interval estimates for self-report mood scales (DASS, DASS-21, HADS, PANAS, and SAD). Br J Clin Psychol, 48(Pt2), 163180.

25 Bouwman, V., Adriaanse, M.C., van't Riet, E., Snoek, F.J., Dekker, J.M., Nijpels, G. (2010). Depression, Anxiety and Glucose Metabolism in the General Dutch Popualtion: The New Hoorn Study. PLoS ONE, 5(4), e9971.

26 Michal, M., Glaesmer, H., Zwerenz, R., Wiltink, J., Brahler, E., Beutel, M.E. (2011). Base rates for depersonalization according to the 2-item version of the Cambridge Depersonalization Scale (CDS-2) and its association with 
depression/anxiety in the general population. J Affect Disord, 128(1-2), 106111.

27 Hinz, A., Brahler, E. (2011). Normative values for the hospital anxiety and depression scale (HADS) in the general German population. J Psychosom Res, 71(2), 74-78.

28 McBeth, J., Chiu, Y.H., Silman, A.J., Ray, D., Morriss, R., Dickens, C., Gupta, A., Macfarlane, G.J. (2005). Hypothalamic-pituitary-adrenal stress axis function and the relationship with chronic widespread pain and its antecedents. Arthritis Res Ther, 7(5), R992-R1000.

29 McBeth, J., Silman, A.J., Gupta, A., Chiu, Y.H., Ray, D., Morriss, R., Dickens, C., King, Y., Macfarlane, G.J. (2007). Moderation of Psychosocial Risk Factors Through Dysfunction of the Hypothalamic-pituitary-adrenal Stress Axis in the Onset of Chronic Widespread Muscuoskeletal Pain. Arthritis Rheum, 56(1), 360-371.

30 Townsend, P., Phillimore, P., Beattie, A. (1988). Health and deprivation: inequalities and the north. London: Croom Helm.

31 The 2001 Census was carried out in April 2001 by the Office of National Statistics. http://www.statistics.gov.uk/census2001/pyramids/pages/uk.asp. Accessed on $11^{\text {th }}$ June 2010.

32 Jones, E.A., McBeth, J., Nicholl, B., Morriss, R.K., Dickens, C., Jones, G.T., Macfarlane, G.J. (2009). What characterises persons who do not report musculoskeletal pain? Results from a four-year population-based longitudinal study (The Epifund Study). J Rheumatol, 36(5), 1071-1077.

33 NHS The Information Centre. Attribution dataset GP registered populations 2010. http://www.ic.nhs.uk/statistics-and-data-collections/population-andgeography/gp-registered-populations/attribution-dataset-gp-registeredpopulations-2010. Accessed 29-Sept-2011. 
34 World Health Organisation website, http://www.who.int/topics/ageing/en/.

Website accessed on 12 April 2010.

35 de Wit, L.M., Fokkema, M., van Straten, A., Lamers, F., Cuijpers, P., Penninx, B.W. (2010), Depressive and anxiety disorders and the association with obesity, physical, and social activities. Depression and Anxiety, 27, 10571065. 


\section{Figure Legends}

Fig 1 Anxiety percentile scores generated from the EpiFunD study compared with those generated from the study providing the currently recommended normative data from the UK [15]. These are presented for females (a) and males (b) separately

Fig 2 Depression percentile scores generated from the EpiFunD study compared with those generated from the study providing the currently recommended normative data from the UK [15]. These are presented for females (a) and males (b) separately 
Figure 1: Comparison of percentiles (anxiety)

(a): Females

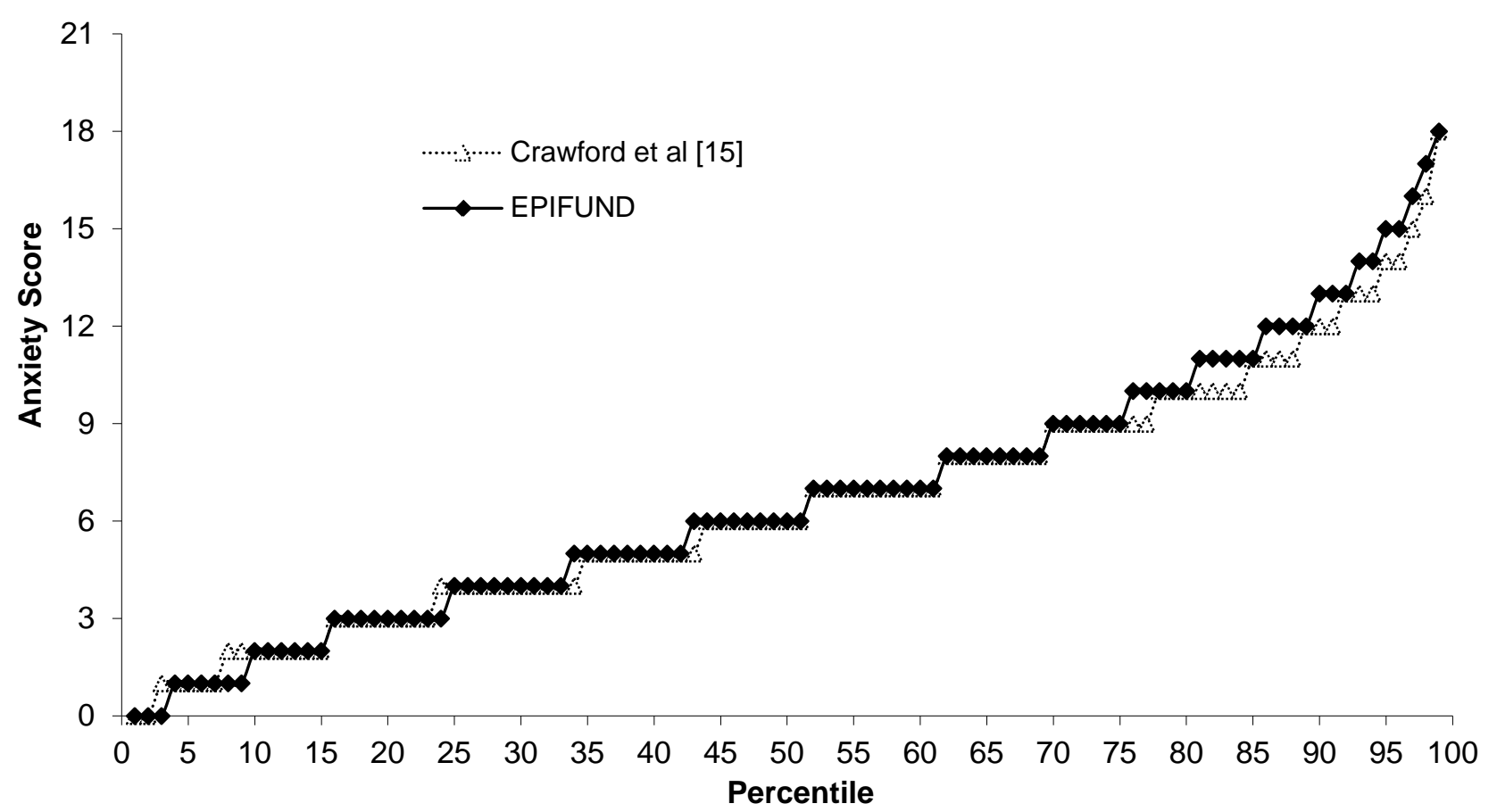

(b): Males

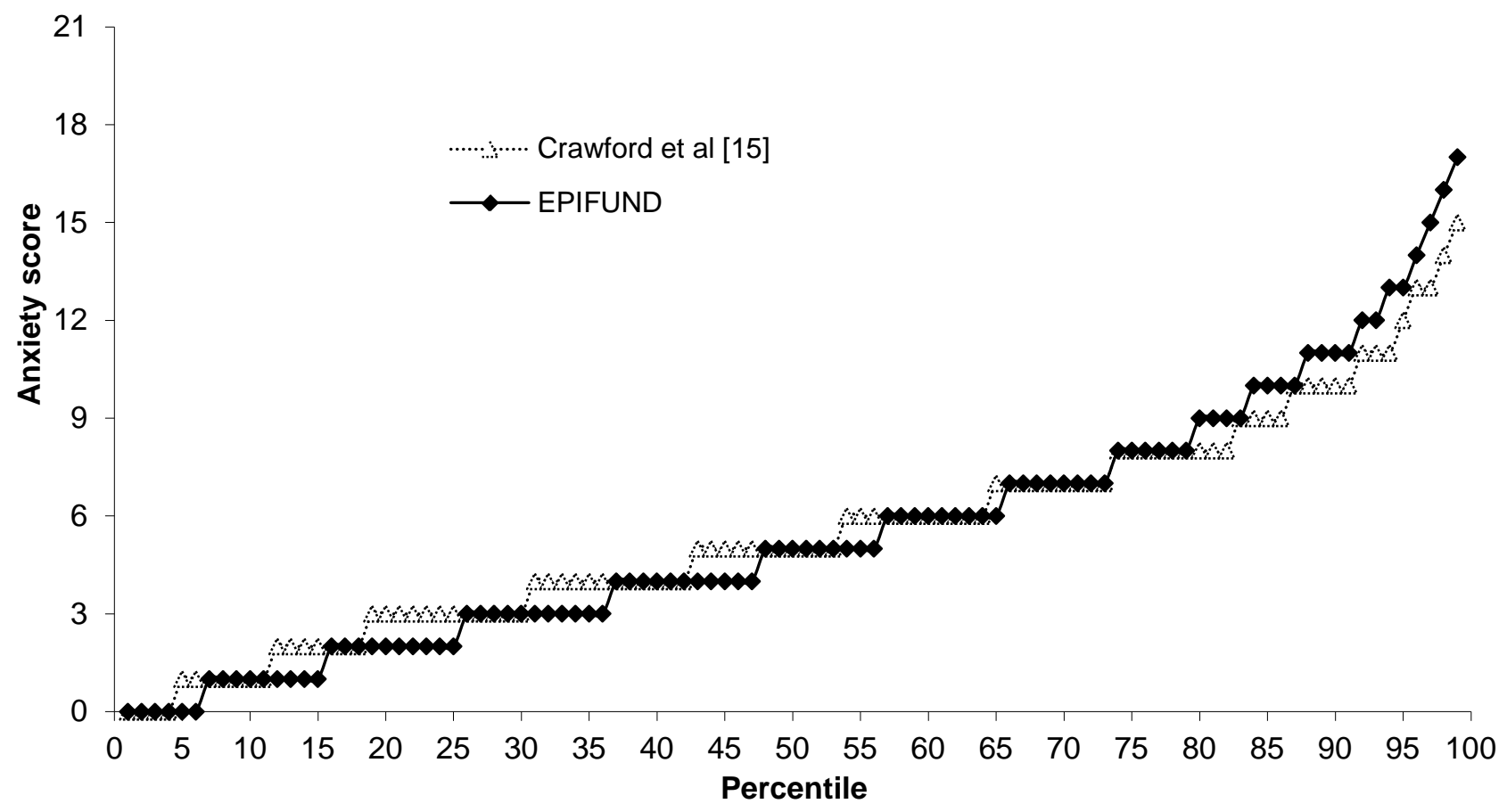


Figure 2: Comparison of percentiles (depression)

(a): Females

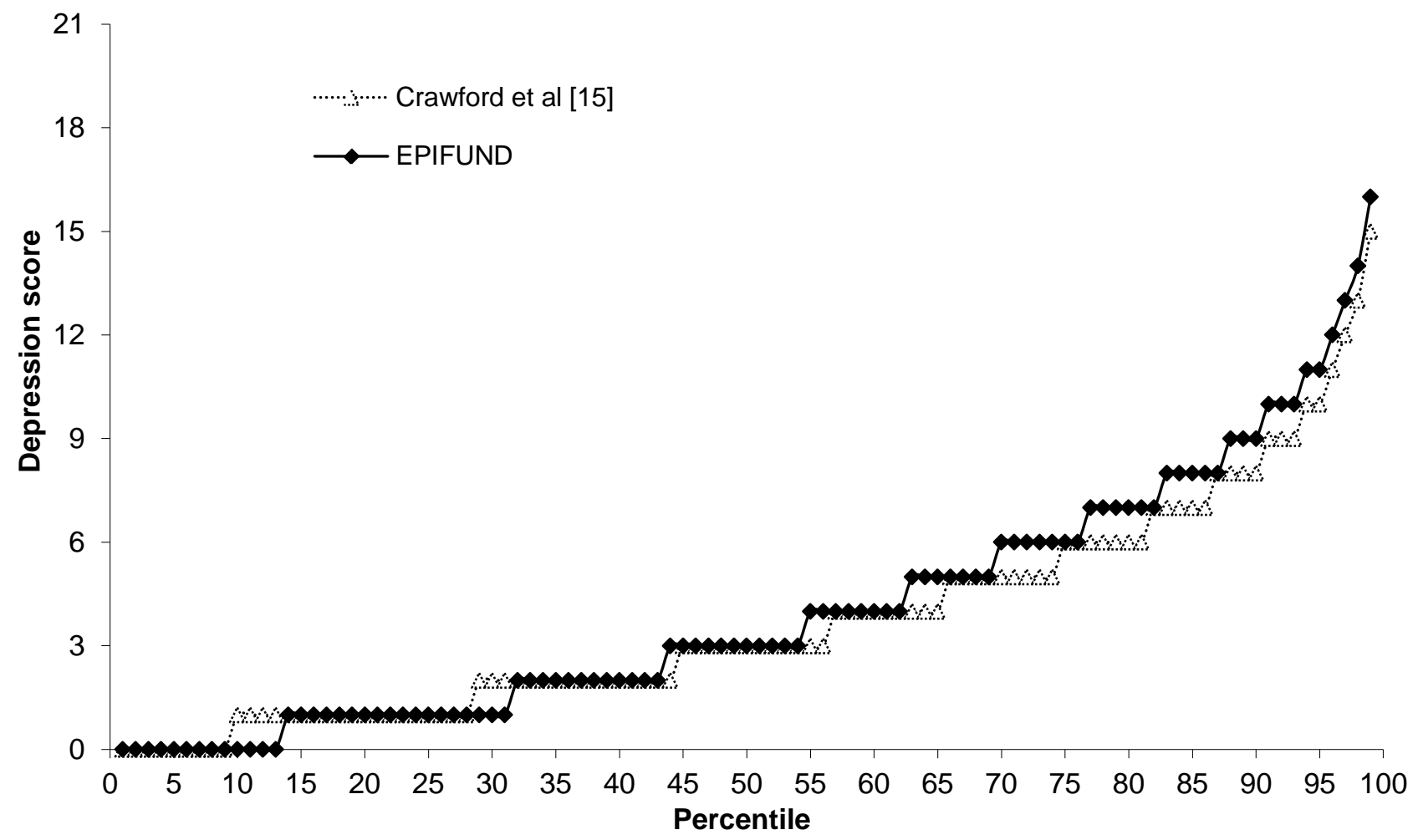

(b): Males

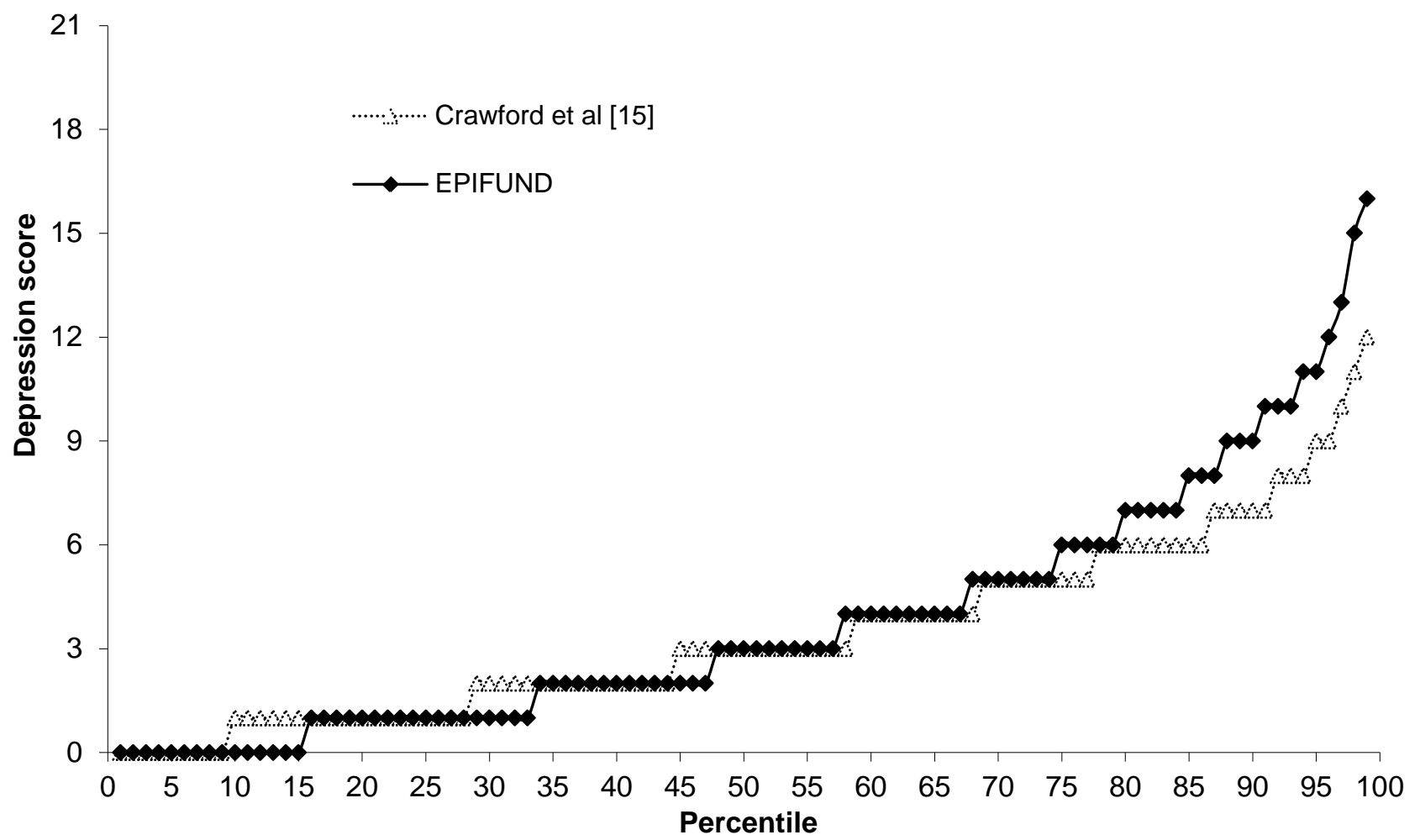


Table 1: Demographics of sample

\begin{tabular}{lrrr} 
& \multicolumn{1}{c}{ Anxiety } & Depression & \multicolumn{1}{c}{$\begin{array}{c}\text { Anxiety and/or } \\
\text { Depression } \\
(\mathrm{n}=6232)\end{array}$} \\
$\begin{array}{lrr}\text { Demographics } \\
\text { Gender }\end{array}$ & $(\mathrm{n}=6189)$ & $(\mathrm{n}=6198)$ & $3519(56.5)$ \\
Female & $3491(56.4)$ & $3503(56.5)$ & $2713(43.5)$ \\
Male & $2698(43.6)$ & $2695(43.5)$ & \\
& & & \\
Age, Mean (SD) & $45.9(11.0)$ & $45.9(11.0)$ & $45.9(11.0)$ \\
Primary care practice & & & \\
Area A (least affluent) & $1342(21.7)$ & $1345(21.7)$ & $1351(21.7)$ \\
Area B (moderately affluent) & $1746(28.2)$ & $1745(28.1)$ & $1760(28.2)$ \\
Area C (most affluent) & $3096(50.0)$ & $3103(50.1)$ & $3116(50.0)$ \\
Unknown & $5(0.1)$ & $5(0.1)$ & $5(0.1)$ \\
Employment Status & $3269(52.8)$ & $3268(52.7)$ & $3282(52.7)$ \\
Working full time & $1023(16.5)$ & $1024(16.5)$ & $1029(16.5)$ \\
Working part time & $408(6.6)$ & $407(6.6)$ & $409(6.6)$ \\
Working full time in the home & $560(9.1)$ & $568(9.2)$ & $571(9.2)$ \\
Not working because of ill health/disability & $120(1.9)$ & $117(1.9)$ & $120(1.9)$ \\
Unemployed but seeking work & $38(0.6)$ & $38(0.6)$ & $38(0.6)$ \\
Student & $112(1.8)$ & $114(1.8)$ & $114(1.8)$ \\
Semi-retired & $511(8.3)$ & $519(8.4)$ & $520(8.3)$ \\
Retired & $148(2.4)$ & $143(2.3)$ & $149(2.4)$ \\
Unknown & & & \\
Marital Status & $910(14.7)$ & $908(14.7)$ & $918(14.7)$ \\
Single & $4397(71.1)$ & $4409(17.1)$ & $4424(71.0)$ \\
Married & $830(13.4)$ & $831(13.4)$ & $838(13.5)$ \\
Other & $52(0.8)$ & $50(0.8)$ & $52(0.8)$ \\
Unknown & & &
\end{tabular}

*Data are presented as number (\%) unless otherwise indicated

${ }^{1}$ Other (separated, divorced and widowed) 
Table 2: Anxiety scores by gender and age

\begin{tabular}{|c|c|c|c|c|c|c|}
\hline \multirow[b]{2}{*}{ Age (yrs) } & \multirow[b]{2}{*}{ N (\%) } & \multirow[b]{2}{*}{ Median (IQR) } & \multicolumn{3}{|c|}{ Percentage (95\% CI) } & \multirow[b]{2}{*}{ Mean (SD) } \\
\hline & & & $\begin{array}{c}\text { Normal } \\
\text { (score 0-7) }\end{array}$ & $\begin{array}{c}\text { Mild } \\
\text { (score 8-10) }\end{array}$ & $\begin{array}{c}\text { Moderate/Severe } \\
(\text { score } \geq 11)\end{array}$ & \\
\hline \multicolumn{7}{|l|}{ Females } \\
\hline $25-65$ & 3491 & $6(4,9)$ & $61.5(59.8-63.1)$ & $19.5(18.2-20.9)$ & $19.0(17.7-20.4)$ & $6.78(4.23)$ \\
\hline $25-29$ & $303(8.7)$ & $7(4,10)$ & $54.5(48.7-60.2)$ & $21.8(17.3-26.9)$ & $23.8(19.1-29.0)$ & $7.18(4.47)$ \\
\hline $30-34$ & 485 (13.9) & $6(4,10)$ & $59.8(55.3-64.2)$ & $20.0(16.5-23.8)$ & $20.2(16.7-24.1)$ & $6.96(4.27)$ \\
\hline $35-39$ & $491(14.1)$ & $6(3,9)$ & $62.5(58.1-66.8)$ & $19.4(15.9-23.1)$ & $18.1(14.8-21.8)$ & $6.74(4.27)$ \\
\hline $40-44$ & $486(13.9)$ & $6(4,9)$ & $61.7(57.2-66.1)$ & $18.1(14.8-21.8)$ & $20.2(16.7-24.0)$ & $6.88(4.29)$ \\
\hline $45-49$ & $451(12.9)$ & $6(4,10)$ & $62.3(57.7-66.8)$ & $18.0(14.5-21.8)$ & $19.7(16.2-23.7)$ & $6.87(4.19)$ \\
\hline $50-54$ & $455(13.0)$ & $6(4,9)$ & $61.3(56.7-65.8)$ & $20.0(16.4-24.0)$ & $18.7(15.2-22.6)$ & $6.78(4.42)$ \\
\hline $55-59$ & $428(12.3)$ & $6(3,9)$ & $61.4(56.7-66.1)$ & $21.3(17.5-25.4)$ & $17.3(13.8-21.2)$ & $6.59(4.15)$ \\
\hline $60-65$ & $392(11.2)$ & $6(3,8)$ & $66.6(61.7-71.2)$ & $18.4(14.7-22.6)$ & $15.0(11.7-19.0)$ & $6.26(3.90)$ \\
\hline \multicolumn{7}{|l|}{ Males } \\
\hline $25-65$ & 2698 & $5(2,8)$ & $73.6(71.9-75.3)$ & $13.9(12.6-15.3)$ & $12.5(11.3-13.8)$ & $5.51(4.04)$ \\
\hline $25-29$ & $174(6.4)$ & $5(2,8)$ & $72.4(65.1-78.9)$ & $13.8(9.0-19.8)$ & $13.8(9.0-19.8)$ & $5.70(4.47)$ \\
\hline $30-34$ & $283(10.5)$ & $5(2,8)$ & 71.7 (66.1-76.9) & $12.7(9.1-17.2)$ & $15.6(11.5-20.3)$ & $5.65(4.05)$ \\
\hline $35-39$ & $358(13.3)$ & $5(3,8)$ & $74.0(69.2-78.5)$ & $14.0(10.5-18.0)$ & $12.0(8.8-15.8)$ & 5.59 (3.92) \\
\hline $40-44$ & $371(13.8)$ & $5(3,8)$ & $70.4(65.4-75.0)$ & $15.6(12.1-19.7)$ & $14.0(10.6-18.0)$ & $6.04(4.12)$ \\
\hline $45-49$ & $401(14.9)$ & $5(3,8)$ & $71.3(66.6-75.7)$ & $14.2(10.9-18.0)$ & $14.5(11.2-18.3)$ & $5.85(4.21)$ \\
\hline $50-54$ & $384(14.2)$ & $5(2,8)$ & $71.6(66.8-76.1)$ & $14.1(10.7-17.9)$ & $14.3(11.0-18.2)$ & $5.59(4.15)$ \\
\hline $55-59$ & 367 (13.6) & $4(2,7)$ & $77.7(73.0-81.8)$ & $13.1(9.8-17.0)$ & $9.3(6.5-12.7)$ & $4.90(3.80)$ \\
\hline $60-65$ & 360 (13.3) & $4(2,7)$ & $79.2(74.6-83.2)$ & $13.3(10.0-17.3)$ & $7.5(5.0-10.7)$ & 4.85 (3.63) \\
\hline
\end{tabular}


Table 3: Depression scores by gender and age

\begin{tabular}{|c|c|c|c|c|c|c|}
\hline \multirow{2}{*}{ Age (yrs) } & \multirow{2}{*}{ N (\%) } & \multirow{2}{*}{ Median (IQR) } & \multicolumn{3}{|c|}{ Percentage (95\% Cl) } & \multirow{2}{*}{ Mean (SD) } \\
\hline & & & $\begin{array}{c}\text { Normal } \\
\text { (score 0-7) }\end{array}$ & $\begin{array}{c}\text { Mild } \\
\text { (score 8-10) }\end{array}$ & $\begin{array}{c}\text { Moderate/Severe } \\
\text { (score } \geq 11)\end{array}$ & \\
\hline \multicolumn{7}{|l|}{ Females } \\
\hline $25-65$ & 3503 & $3(1,6)$ & $82.8(81.5-84.1)$ & $10.3(9.3-11.3)$ & $6.9(6.1-7.8)$ & $4.12(3.78)$ \\
\hline $25-29$ & 307 (8.8) & $3(1,6)$ & 83.1 (78.4-87.1) & $10.4(7.2-14.4)$ & $6.5(4.0-9.9)$ & $3.86(3.78)$ \\
\hline $30-34$ & $483(13.8)$ & $3(1,6)$ & $84.5(80.9-87.6)$ & $9.5(7.1-12.5)$ & $6.0(4.1-8.5)$ & $3.92(3.70)$ \\
\hline $35-39$ & $490(14.0)$ & $3(1,6)$ & $80.8(77.0-84.2)$ & $13.1(10.2-16.4)$ & $6.1(4.2-8.6)$ & $4.16(3.83)$ \\
\hline $40-44$ & $489(14.0)$ & $3(1,7)$ & $80.8(77.0-84.2)$ & $10.8(8.2-13.9)$ & $8.4(6.1-11.2)$ & $4.21(4.02)$ \\
\hline $45-49$ & $452(12.9)$ & $3(1,6)$ & $82.1(78.2-85.5)$ & $10.6(7.9-13.8)$ & $7.3(5.1-10.1)$ & $4.28(3.98)$ \\
\hline $50-54$ & 455 (13.0) & $3(1,6)$ & $81.2(78.1-85.4)$ & $9.9(7.3-13.0)$ & $8.1(5.8-11.0)$ & $4.27(3.91)$ \\
\hline $55-59$ & $428(12.2)$ & $3(1,6)$ & $85.0(81.3-88.3)$ & $7.5(5.2-10.4)$ & $7.5(5.2-10.4)$ & $4.05(3.61)$ \\
\hline $60-65$ & $399(11.4)$ & $3(1,6)$ & $85.0(81.1-88.3)$ & $10.0(7.3-13.4)$ & $5.0(3.1-7.6)$ & $4.07(3.30)$ \\
\hline \multicolumn{7}{|l|}{ Males } \\
\hline $25-65$ & 2695 & $3(1,6)$ & $84.6(83.1-85.9)$ & $8.5(7.5-9.6)$ & $6.9(6.0-8.0)$ & $3.83(3.74)$ \\
\hline $25-29$ & $173(6.4)$ & $2(1,4)$ & $89.0(83.4-93.3)$ & $6.4(3.2-11.1)$ & $4.6(2.0-8.9)$ & $3.04(3.62)$ \\
\hline $30-34$ & $285(10.6)$ & $2(1,5)$ & $88.1(83.7-91.6)$ & $7.0(4.3-10.6)$ & $4.9(2.7-8.1)$ & $3.42(3.38)$ \\
\hline $35-39$ & $359(13.3)$ & $3(1,5)$ & $89.1(85.4-92.2)$ & $5.9(3.7-8.8)$ & $5.0(3.0-7.8)$ & $3.54(3.41)$ \\
\hline $40-44$ & 368 (13.7) & $3(1,6)$ & $82.9(78.6-86.6)$ & $8.4(5.8-11.7)$ & $8.7(6.0-12.1)$ & $4.04(3.96)$ \\
\hline $45-49$ & 402 (14.9) & $3(1,6)$ & $82.3(78.3-85.9)$ & $9.7(7.0-13.0)$ & $8.0(5.5-11.1)$ & $4.05(4.02)$ \\
\hline $50-54$ & 381 (14.1) & $3(1,6)$ & $80.6(76.2-84.4)$ & $10.5(7.6-14.0)$ & $8.9(6.3-12.2)$ & $4.33(4.09)$ \\
\hline $55-59$ & $363(13.5)$ & $3(1,5)$ & $84.6(80.4-88.1)$ & $8.8(6.1-12.2)$ & $6.6(4.3-9.7)$ & $3.76(3.57)$ \\
\hline $60-65$ & 364 (13.5) & $3(1,6)$ & 83.5 (79.3-87.2) & $9.6(6.8-13.1)$ & $6.9(4.5-10.0)$ & $3.93(3.56)$ \\
\hline
\end{tabular}

